\title{
FAMÍLIAS HOMOAFETIVAS: DA LACUNA LEGAL À DECISÃO HISTÓRICA DO STF
}

\author{
HOMOAFFECTIVE FAMILIES: FROM THE LEGAL GAP TO THE \\ HISTORICAL DECISION TAKEN BY THE FEDERAL SUPREME COURT
}

\author{
Izabel Cristina Philipovsky ${ }^{1}$ \\ Juliana Gonzales Spinardi Alonso \\ Sandra Mara Dias Pedroso ${ }^{3}$
}

Data de envio: $22 / 05 / 2012$

Data de aceite: 12/07/2012

\begin{abstract}
RESUMO
O presente artigo objetiva apontar as transformações ocorridas na estrutura familiar ao longo dos tempos. Conforme os diferentes momentos históricos e fatores econômicos, religiosos ou sociopolíticos vigentes, o arcabouço familiar sofreu modificações. O modelo de composição familiar hierarquizada e desenvolvida ao redor do patriarca acabou cedendo espaço a uma família na qual o poder passou a ser distribuído igualitariamente entre seus membros. Com a modernização da sociedade, a família se nuclearizou, chegando às mais diversas estruturas relacionais, levando ao surgimento de configurações familiares plurais. Passou, portanto, a existir uma nova concepção de família, associada não apenas a fatores biológicos ou civis, mas, de maneira especial, focada no vínculo da afetividade como elemento imprescindível para sua manutenção, independentemente do sexo das pessoas envolvidas. Desse modo, as uniões homoafetivas são um fato social e, não fosse a exigência imposta pela lei quando ao conceituar união estável exigiu a diversidade de sexos, as uniões homoafetivas em nada mais a ela seriam diferentes. Por ambas possuírem como base do relacionamento a vida em comum, o respeito, a solidariedade, a mútua assistência, vínculos em que há comprometimento amoroso e afetivo, seria correto aplicar às uniões homoafetivas a legislação concernente à união estável, equiparando-as por analogia. Com a transformação da sociedade, essas novas configurações familiares passaram a buscar visibilidade e a exigir do Estado proteção jurídica. Essa busca por direitos culminou com a decisão histórica do Supremo Tribunal Federal, que estendeu às uniões homoafetivas todos os direitos já chancelados às uniões heteroafetivas, o que representou uma quebra de paradigmas. Não cabe ao Estado a negação da proteção jurídica, tampouco colocar à margem da própria cidadania as uniões homoafetivas, cerceando-lhes liberdades, porque isto descaracterizaria por completo um Estado democrático de direito.
\end{abstract}

Palavras-chave: Uniões homoafetivas. União estável. Família. Afeto.

\footnotetext{
Faculdade Educacional de Ponta Grossa - Faculdade União. E-mail: <ic_philip@hotmail.com>

Faculdade Educacional de Ponta Grossa - Faculdade União. E-mail: <juliana spinardi@hotmail.com>

Faculdade Educacional de Ponta Grossa - Faculdade União. E-mail: <sandra@uniao.edu.br>
} 


\begin{abstract}
This article aims to demonstrate the transformations undergone by families over time. Families have changed according to different historical and economic factors; religious or socio-political frameworks. The hierarchical model of family composition developed around the patriarch eventually gave way to a family in which the power is now distributed equally among its members. With the modernization of society the family became a nuclear institution with several relational structures, leading to the emergence of plural family configurations. As a consequence, a new conception of family emerged, associated not only to biological or civilian aspects, but especially focused on the bond of affection as an indispensable element for its maintenance, regardless of the gender of those involved. Therefore, homoaffective unions are a social fact. The only difference between a stable union and the homoaffective ones is that these are not based on gender differences, which is a definition required by the law. Both forms of union are based on sharing a common life, respect, solidarity, commitment and affective bonds. It seems reasonable to expect that the legislation should be applied to both types of stable unions as a form of giving them the same status. With society's transformations, these new family configurations seek for visibility and demand the state's legal protection. This demand for rights ended up in a historical decision taken by the Federal Supreme Court that extended to homoaffective unions all the rights heteroaffective ones have, which represents a shift in paradigms. The State can't deny legal protection, nor exclude homoaffective unions from their right of citizenship, nor restrict their right to freedom, as this would completely destroy the characteristics of a democratic state.
\end{abstract}

Keywords: Homoaffective unions. Stable union. Family. Affection.

\section{Introdução}

Os vínculos advindos das relações homoafetivas são um fenômeno profundamente visível na sociedade, e conquanto ainda permaneçam resistências impedindo que sejam disciplinados direitos sobrevindos destas relações, seria desumano não asseverar equidade a este segmento social tão marginalizado.

A ausência de regramento específico não significa ausência de direito, pois existem mecanismos para suprir as lacunas legislativas, aplicando-se aos casos concretos a analogia, os costumes e os princípios gerais de direito em consonância com os preceitos constitucionais. Cabe, portanto, ao magistrado atuar na lacuna normativa, ressaltando-se que a finalidade última do ato de julgar consiste em fazer justiça, dando a cada indivíduo que busca o judiciário uma resposta ao que anseia.

Os princípios basilares da dignidade humana, da liberdade, da igualdade substancial, da não discriminação, inclusive por orientação sexual, e o pluralismo familiar, muito comum hoje na sociedade, devem ser ressaltados e uma decisão judicial que negue direitos e legitime injustiças é ilegal e, portanto, juridicamente insustentável.

Quando relacionamentos homoafetivos chegam ao Judiciário, não encontram previsão legal para solucionar o caso concreto. Assim, diante da lacuna existente, se torna imprescindível a utilização dos recursos disponíveis para propiciar previsibilidade nas condutas e estabilidade das relações.

A Carta Magna de 1988 é taxativa ao considerar como família somente o vínculo formado pelo casamento, pela união estável e a monoparentalidade. Com isso, no ordenamento, a união de duas pessoas do mesmo sexo, que se assistem e amparam mutuamente, com o respeito e o afeto recíproco em uma convivência duradoura, pública, contínua, não é considerada uma família, e sim, na melhor das hipóteses, uma sociedade.

Não obstante o indicador de mudança comportamental, se constata que, no plano do direito, por 
praxe conservadora, a questão da possibilidade do reconhecimento das uniões homoafetivas ainda tem gerado muita polêmica. Ocorre que o direito acaba trazendo decisões díspares sobre o tema, frente à omissão legal, em que a mente do julgador ora se posiciona no sentido de não reconhecer efeitos a essas uniões, por supostamente não serem albergadas pelo direito pátrio, ora reconhecendo efeito similar à união estável heterossexual.

Diante das colocações acima, o presente artigo discorre sobre o direito de família no Brasil, as novas configurações familiares, culminando com a comparação analógica entre união estável e união homoafetiva.

\section{O direito de família no Brasil}

A espécie humana, diferentemente dos animais, não dispõe de um sistema biológico que por si só proporcione estabilidade social ao grupo. A incompletude do ser humano é suprida pelas instituições sociais, que determinam ao grupo normas de conduta preestabelecidas, e é na esfera da família que as relações sociais são instituídas e fortemente se evidenciam, impondo normas obviamente, constituindo noções sempre relativas ao tempo e ao espaço.

A família é a instituição fundamental e imprescindível na formação do indivíduo. Ela é seu referencial na sociedade e no mundo, sendo inquestionável seu papel na formação da identidade, da afetividade e da sexualidade de seus membros.

Para Prado,

a família não é um simples fenômeno natural, ela é uma instituição social variada através da história, apresentando formas e finalidades diversas numa época e lugar, conforme o grupo social que esteja sendo observado. (PRADO, 1995, p. 12).

Como elemento inserido na sociedade, a família também se transforma, assumindo características diferenciadas dependendo do grupo e do momento em que é analisada, e sua competência e habilidade residem em organizar, dar forma e significado às relações de seus integrantes, passando por incontáveis transformações ao longo da história.

No Brasil, a instituição familiar inicialmente apresentava um caráter patriarcal: os membros se submetiam à autoridade soberana do pai, e toda a vida familiar orbitava ao seu redor, constituindo assim o centro de gravidade de seus domínios e das pessoas que os habitavam.

A primazia da organização familiar era do homem e, ocupando uma posição secundária, estava a mulher do patriarca. Raramente conseguia ter destaque na vida familiar, porém algumas poucas conseguiam assumir as funções do patriarca quando este ainda estava vivo ou após sua morte: eram consideradas verdadeiras fortalezas, responsáveis pela educação dos filhos e a administração das propriedades, se revelaram líderes, com uma capacidade administrativa admirável.

Havia mulheres que assumiam sua independência e, contrariando a normas impostas pela sociedade da época, optavam por estudar, trabalhar, iniciativa que não era bem aceita, principalmente por fugir totalmente aos padrões vigentes.

Os casamentos eram caracteristicamente arranjos de conveniência, em que cada família patriarcal formava um grande núcleo de interesses próprios, dominando vastas extensões territoriais e criando, muitas vezes, verdadeiros impérios patrimoniais.

A sociedade apenas considerava como família legítima a originária do casamento e, independentemente de religião, o casamento civil passa a ser o único possuidor de validade perante as autoridades civis. Conforme enfatiza Bittar Filho:

Durante séculos, a família patriarcal foi a organização familiar básica do povo brasileiro. Podemos dizer, sem risco de erro, que, ao lado da Igreja, a família patriarcal foi a mais forte instituição brasileira até o começo do século XX. Foi dentro do universo patriarcal que muitos brasileiros, ao longo de nossa história, foram criados. Isso significa que, por cerca de 400 anos (do século XVI ao princípio do século XX), a cultura patriarcal, marcada pela nítida predominância do individual sobre o coletivo, foi o grande modelo de vida para os brasileiros. (BITTAR FILHO, 2008).

Até o início do século XX, a família e a Igreja foram as instituições de maior poder na sociedade brasileira, sendo incontáveis as famílias que se desenvolveram dentro do padrão patriarcal. Foi só a partir da segunda metade do século XIX que esse modelo de família teve suas bases enfraquecidas, acabando por se deteriorar. A Revolução Industrial 
constitui o divisor de águas responsável pelo processo de modificação da família, contribuindo sobremaneira para o crescente processo da chamada desagregação familiar.

Bittar Filho apud Franchini (2004, p. 201) destaca que os movimentos de emancipação da mulher e dos jovens, a urbanização acelerada, a industrialização e as revoluções tecnológicas, as profundas modificações econômicas e sociais ocorridas na realidade brasileira e as imensas transformações comportamentais havidas puseram fim à instituição familiar nos moldes patriarcais.

Houve uma transformação na relação familiar e no comportamento do ser humano no meio social e, com isso, passou-se a não mais espelhar um modelo exclusivo de família: o casamento, ancorado no autoritarismo patriarcal e na desigualdade, acabou por ruir.

Chiletto (2007) explica que a nova família não é apenas o seio da imortalidade dos vínculos consanguíneos, da defesa do nome e de bens patrimoniais dos antepassados, objetivos que, antigamente, se estabeleciam na razão de ser de toda a sua constituição.

Atualmente a instituição familiar se apresenta organizada e restrita a um número reduzido de pessoas, e a família extensa foi definitivamente suplantada pela família nuclear, mesmo porque a tendência é a busca cada vez maior pela privacidade.

A Constituição Brasileira de 1988 absorveu essa transformação e fez uma verdadeira revolução no direito de família a partir de três eixos básicos (PEREIRA, 2008).

O primeiro eixo da revolução constitucional deixou claro que a família no limiar do terceiro milênio é plural e não mais singular; de acordo com o artigo 226 da Constituição Federal de 1988, existem novas configurações familiares: família matrimonial, o casamento. Segundo Kümpel, “[...] a família matrimonial decorre do casamento como ato formal, litúrgico. Até 1988, era o único vínculo familiar reconhecido no país [...]" (KÜMPEL, 2008).

Assim se formam duas teorias: a primeira, que assinala ser o casamento o principal vínculo de família; e a segunda, que defende o princípio da isonomia entre os vínculos familiares, estabelecendo o casamento apenas como uma das formas de família.

A união estável, entendida como a relação entre homem e mulher que não tenham impedimento para o casamento, é assim definida pelo artigo 1.723 do Código Civil:

Art. 1.723. É reconhecida como entidade familiar a união estável entre o homem e a mulher, configurada na convivência pública, contínua e duradoura e estabelecida com o objetivo de constituição de família.

$\S 1 .^{\circ}$. A união estável não se constituirá se ocorrerem os impedimentos do art. 1.521; não se aplicando a incidência do inciso VI no caso de a pessoa casada se achar separada de fato ou judicialmente.

$\S 2 .^{\circ}$. As causas suspensivas do art. 1.523 não impedirão a caracterização da união estável.

A família monoparental é caracterizada pelo artigo 226, § $4^{\circ}$, da Constituição Federal, nestes termos: "Entende-se, também, como entidade familiar a comunidade formada por qualquer dos pais e seus descendentes." A família contemporânea não se depara mais com uma única maneira de se manifestar e diariamente se esbarra em uma realidade de vínculos familiares e afetivos que foge totalmente aos padrões aos quais se estava acostumado.

O segundo eixo da revolução constitucional representa, no direito de família pátrio, um avanço que deve ser enaltecido, porque põe fim à deplorável hipocrisia da época ao ousar proibir designações discriminatórias sobre os filhos, ao alterar o sistema de filiação, pois, além de juridicamente iguais, os filhos hoje gozam de especial atenção da ordem constitucional. Não há que se falar mais em filhos legítimos ou ilegítimos: "Os filhos, havidos ou não da relação do casamento, ou por adoção, terão os mesmos direitos e qualificações, proibidas quaisquer designações discriminatórias relativas à filiação." Este é o preceito contido no $\S 6^{\circ}$ do artigo 227 da Constituição Federal.

Atualmente, se fala em filhos havidos dentro ou fora do casamento apenas para garantir a estes últimos a possibilidade do reconhecimento. Esta é a designação usual e politicamente correta (qualquer outra expressão ou rótulo seria pejorativo e, portanto, discriminatório). Os filhos terão sempre os mesmos direitos, não mais podendo haver quaisquer distinções ou designações discriminatórias. Não poderá existir qualquer diferença ou categoria também com relação aos direitos patrimoniais dos filhos. 
O terceiro eixo da revolução constitucional reside nos artigos 5. ${ }^{\circ}$, I ("homens e mulheres são iguais em direitos e obrigações, nos termos desta Constituição") e $226, \S 5 .^{\circ}$ ("Os direitos e deveres referentes à sociedade conjugal são exercidos igualmente pelo homem e pela mulher").

A consequência foi a elaboração de vários artigos do Código Civil pátrio:

As mudanças são mesmo muito difíceis admiti-las significa repensar modelos, paradigmas e abrir mão de determinados poderes instituídos. Devemos nos acautelar e desconfiar sempre daqueles resistentes às mudanças, e que se posicionam como os guardiões de uma moralidade, como por exemplo, alguns profissionais do direito que chegam a afirmar que as novas leis sobre a união estável são um incentivo à promiscuidade. (KÜMPEL, 2008).

Toda postura conservadora traz em si uma resistência sistemática às mudanças, pois, em certos casos, mudar conceitos, formas de pensar e agir significa perda de poder na sociedade, e pessoas com essas formas de comportamento são incontáveis. $\mathrm{O}$ indivíduo que possui comportamento inflexível normalmente assume o papel de guardião da moralidade, resistindo a tudo que signifique uma ameaça aos seus rígidos padrões.

Considerando que as mudanças nem sempre são fáceis, certamente são imprescindíveis, pois contribuem para que novos conceitos sejam incorporados à sociedade, que, estando em constante transformação, faz surgir novos modelos sociais que vão se delineando, objetivando cada vez mais a defesa da dignidade do ser humano, buscando atender plenamente a seus anseios.

Os princípios que inspiram a nova família espelham uma nova maneira de olhar, que vai além da concepção transpessoal, enaltecida pela visão eudemonista pela qual valores como o amor, a solidariedade e a convivência amoldam o viver em família como comunidade de afeto.

As transformações nos rumos e formas de constituição da família atual são apenas a expressão e a reivindicação da ampliação do espaço de liberdade das pessoas. E a liberdade é um dos pilares que sustenta o direito.

\section{As novas configurações familiares}

A humanidade, desde o início de sua existência, vem evoluindo, e o mundo contemporâneo passa por transformações extremamente significativas, com avanços tecnológicos, científicos e principalmente culturais que contribuem na promoção dessas mudanças. Tais mudanças acabam por se refletir também na família, que atualmente traduz um relacionamento baseado não mais no casamento, mas sim no afeto, na comunicação emocional, no amor. A nova família procura proteger seus indivíduos de preconceitos, preserva a liberdade de expressão, visando, e principalmente garantindo, o respeito à dignidade do ser humano, independentemente de suas escolhas.

Os modelos em que a família era identificada pelo casamento com a finalidade procriativa foram rompidos, devido à emancipação da mulher, à evolução dos costumes, ao surgimento dos métodos contraceptivos, à própria globalização, entre outras razões que levaram à reformulação da estrutura da família que passa a ser vista como um espaço de afetividade e não mais exclusivo da conjugalidade.

Ressalte-se, entretanto, que nada está posto e definitivo, pois mudanças dessa natureza se dão em meio a conflitos e resistências. O momento atual é de transição, em que este novo modelo de família ainda está sendo consolidado, e o ordenamento jurídico necessita urgentemente se adequar a este novo formato de família, objetivando atender aos anseios da sociedade.

O modelo clássico de família, assim, vai cedendo espaço à concepção contemporânea de família. $\mathrm{O}$ antigo sistema familiar composto tão somente pelas figuras paterna, materna e pelos filhos advindos da relação matrimonial não mais prevalece, e hoje a sociedade se depara com a ruptura dos tabus familiares, com desbiologização da paternidade, os filhos de laboratório:

Qual seria, hoje, a dimensão conceitual mais justa e mais adequada de família, para que efetivamente fossem cumpridos os princípios constitucionais básicos da nação brasileira? Talvez devêssemos caracterizar família como a união de duas pessoas, independente do seu sexo, com convivência duradoura e contínua, baseada no respeito e consideração, com o objetivo de sua realização afetiva. (SIMON, 2008). 
Atualmente se busca um conceito apropriado de família em que haja a definição adequada às novas configurações existentes, baseado na mudança da própria sociedade; um conceito em que sejam respeitados os preceitos constitucionais e que sejam desprovidos de características exclusivistas ou discriminatórias.

A ordem jurídica não pode se furtar ao reconhecimento de um modelo familiar plural e, neste novo contexto, as normas jurídicas de família passarão a possuir a natureza de ordem pública, cujas condutas institucionais, no âmbito doutrinário, devem ser responsáveis por garantir a segurança das relações humanas, para que as pessoas possam coexistir e se entender entre si.

Por refletir fatores psíquicos materializados no âmbito da afetividade e da sexualidade, a família atualmente passa a ser vista como um fenômeno sociocultural, cabendo ao direito incorporar as transformações pelas quais passa a nova família, dispensando um tratamento adequado que atenda a suas necessidades quando estas novas estruturas buscarem a prestação jurisdicional.

O desafio hoje apresentado ao direito de família é incorporar o pluralismo e corresponder aos objetivos que lhe são confiados. Embora a Constituição tenha albergado em seu mais recente texto novas configurações familiares, infelizmente não o fez de forma a incluir todas as uniões afetivas presentes em nossa sociedade.

Inegável é que as relações familiares hoje se vinculam não só pelo sangue, mas por amor e carinho. A presença de um vínculo afetivo leva ao enlaçamento das vidas, o que deve se revelar suficiente para que se reconheça a existência de uma família.

Assim, qualquer outro requisito ou pressuposto é desnecessário para sua identificação e para que possa haver um convívio social harmônico, e as pessoas envolvidas nestas relações esperam que a sociedade lhes retribua respeito:

A afetividade traduzida no respeito de cada um por si e por todos os membros, a fim de que a família seja respeitada em sua dignidade e honorabilidade perante o corpo social, é, sem dúvida nenhuma, uma das maiores características da família atual. (OLIVEIRA, 2002, p. 384).

No momento em que outros relacionamentos além dos decorrentes do casamento se ajustam ao conceito de família, nada mais legítimo que inserir no âmbito do direito de família outro gênero de vínculo: as relações homoafetivas. Embora estes relacionamentos ainda sejam alvo de rejeição social, não podem receber do Poder Judiciário um tratamento discriminatório e preconceituoso:

Hoje em dia, Sagrada Família é apenas um quadro na parede, e a composição clássica de família também é coisa do passado. O que há agora são famílias que nada mais são que o resultado de combinações completamente inovadoras como as relações homoafetivas, a união estável ou a família parental. A interpretação judicial sobre as uniões homoafetivas pode vir a criar a quarta família brasileira. Parece muito confuso, pois a confusão é ainda maior quando se sabe que toda esta revolução de costumes está se desenrolando sem um marco legal. (DIAS, 2008).

Como bem observa o autor citado, a composição clássica de família ficou no passado, já que atualmente, diante da revolução de costumes que operam na sociedade, novas configurações familiares se evidenciam. Assim, diante de tantas mudanças ocorrendo de forma tão rápida, é natural que haja certa confusão, especialmente com relação ao tratamento mais apropriado que se deve dar às novas relações.

É neste vazio de leis que emerge o Judiciário, surpreendentemente ativo para ditar caminhos e marcar posições. Com dificuldades próprias de quem está movimentando e removendo crenças e hábitos ancestrais, são os juízes e não os legisladores que estão construindo o novo direito de família, ou o novo direito das muitas famílias que agora se configuram.

Lamentavelmente, a lei não consegue acompanhar o desenvolvimento social cada vez mais acentuado, e as relações afetivas são as mais sensíveis à evolução dos valores e conceitos, escapando (por assim dizer) ao direito positivado, uma vez que o legislador não tem condições de prever tudo o que é digno de regramento.

\section{União estável e união homoafetiva: compa- ração analógica}

As uniões extramatrimoniais entre homem e mulher sempre existiram, nas mais diversas sociedades desde a Antiguidade, havendo relatos de notórios concubinatos que, de certa forma, tinham 
o reconhecimento legal. Também em Roma estas uniões se fizeram presentes, embora fossem consideradas inferiores ao casamento e desprovidas de efeitos jurídicos, por serem informais, e ainda assim eram tidas como lícitas, não sendo condenadas socialmente.

Tais uniões eram observadas durante a Idade Média e, mesmo sendo repudiadas pela Igreja e tidas pela sociedade como reprováveis e imorais, eram toleradas.

No Brasil, foi extenso o caminho percorrido pelas uniões estáveis até atingirem o atual patamar constitucional, pois por muito tempo as relações não oriundas do casamento acabavam sofrendo críticas implacáveis, sendo alvo de discriminação pela sociedade pseudomoralista, pela Igreja e seus ultrapassados valores ético-morais e também pelo Estado, que, impassível, ignorava o apelo social dessas configurações familiares tão comuns na realidade cotidiana.

Giselda Fernandes Hironaka expressa que

nos custou muito, na época em que vivemos, obter o passaporte da aceitabilidade e o alvará da respeitabilidade para estas uniões, às quais, na atualidade, têm se convencionado denominar união estável. (HIRONAKA, 2008).

O reconhecimento constitucional da união estável percorreu, assim como as uniões homoafetivas, um longo caminho de preconceitos, mas, diferentemente desta última, encontrou maior acolhida, não só pela sociedade como também nos textos normativos existentes. Uma legislação própria para regulamentar a união estável se tornou necessária até mesmo para respeitar a entidade familiar.

A primeira condição para regulamentá-la seria a união entre sexos opostos, segundo os artigos 226, § 3. ${ }^{\circ}$, da Constituição Federal, e 1.723, do Código Civil, seguindo a convivência duradoura, pública, com aspectos de constituição de uma família. Portanto, o reconhecimento das uniões homoafetivas não se encontra passível de interpretação sob os auspícios das normas regulamentadoras da união estável:

As limitações constitucionais alteradas para reconhecer a união estável como entidade familiar, cercou-se de cuidados quanto à expressa relação entre um homem e uma mulher, restando prejudicada uma interpretação analógica, como seria se comparássemos aos casais homoafetivos. O legislador consolidou a realidade emergente da união estável sob os moldes da família tradicional. (MELO, 2009).

A união estável teve seu reconhecimento cercado de cuidados: ao legitimar a relação entre o homem e a mulher, e tão somente, o legislador acabou comprometendo a comparação analógica das uniões homoafetivas com aquela.

Como ensina Maria Cristina de Brito Lima,

[...] a união estável difere do casamento por ser uma sociedade de fato sem se sujeitar as exigências formais, bastando provar sua existência para o seu reconhecimento, enquanto que o casamento somente se constitui após a celebração, sendo um ato formal por natureza, provada sua existência pela certidão de casamento. (LIMA, 2008).

Quando o legislador alargou o conceito de $f a$ mília para reconhecer a união estável, tomou as devidas precauções a fim de não comprometer o Estado claro que para isso teve o amparo de situações de fato existentes, embora polêmicas, perante a sociedade.

Portanto, as uniões homoafetivas anteriores à decisão do STF não eram vistas como um tipo de entidade familiar por alguns doutrinadores, que certamente ignoravam ou deixavam de observar alguns princípios constitucionais, como o da liberdade, da isonomia ou o da igualdade. Sobre uniões homoafetivas, Taísa Ribeiro Fernandes expõe que

[...] no sentido de que há identidade de situações entre as uniões homoafetivas e heteroafetivas, visto que ambas são pautadas pela vida em comum, respeito, afeto, solidariedade, mútua assistência e tantos outros, donde, superada a letra fria do texto normativo e tendo em conta a sua substância, seu fim social (em suma, digo eu, sua interpretação teleológica) percebe-se que as uniões homoafetivas representam efetivas entidades familiares e têm, portanto, que receber o mesmo tratamento jurídico dispensado às uniões heteroafetivas, razão pela qual é cabível o recurso analógico para isto possibilitar. (FERNANDES, 2008).

Não existem motivos para que não se dê às uniões homoafetivas o mesmo tratamento dado às uniões heteroafetivas, inclusive equiparando-as, pois em ambas a base do relacionamento se pauta na vida emocional e no afeto. No entanto, isso não foi suficiente para que a lei priorizasse tais condições como 
requisito para o reconhecimento desses casais como uma família.

Constitui união homoafetiva a relação fática entre duas pessoas do mesmo sexo, configurada na convivência pública, contínua, duradoura e estabelecida com o objetivo de constituir verdadeira família, observados os deveres de lealdade, respeito e mútua assistência.

Para alguns doutrinadores, as uniões homoafetivas possuem características semelhantes às uniões estáveis, pois entendem eles que o principal elemento constituidor da família é o afeto, e nesse sentido Carbonera expõe:

Com a instalação da igualdade e da liberdade na família, o vínculo jurídico cedeu parte de seu espaço à verdade socioafetiva. Felicidade e afeto demarcaram seu espaço na noção jurídica de família em todas as esferas, a exemplo do que já havia acontecido na realidade social. Da família matrimonializada por contrato chegou-se à família informal, precisamente porque afeto não é um dever e a coabitação uma opção, um ato de liberdade. (CARBONERA, 1998, p. 291).

O que existe hoje nas relações familiares é o vínculo de afeto. Em função disso, fica caracterizada uma resistência menor quanto ao reconhecimento das uniões homoafetivas à realização de um contrato de convivência, semelhante ao que ocorre com a formação daquelas que já são reconhecidas por lei.

Pessoas do mesmo sexo podem formar sociedades de fato e se enquadram no contexto do artigo 981 do Código Civil, segundo o qual "celebram contrato de sociedade as pessoas que reciprocamente se obrigam a contribuir, com bens ou serviços, para o exercício de atividade econômica e a partilha, entre si, dos resultados".

Porém, uma vez que, se a norma acima mencionada preconiza a conjugação de capital e esforços com fim econômico, estaria sendo atribuída às relações homoafetivas natureza de cunho friamente patrimonial, sem garantias do direito de família. Assim, a interpretação da convivência dessas relações diante do dispositivo citado não encontra guarida quando considerado o desprezo da situação afetiva.

Desse modo, se tornou necessária a discussão quanto ao reconhecimento dessas uniões como uma sociedade, a qual poderá se formalizar mediante um instrumento contratual ou, ainda, concebendo-a como uma instituição do direito de família, fazendo-se acompanhar os princípios do direito das obrigações, o que faz recordar uma discussão similar: a natureza jurídica das sociedades conjugais.

A doutrinadora Maria Berenice Dias, com extrema lucidez, expõe:

Não há como deixar de visualizar a possibilidade do reconhecimento de uma união estável entre pessoas do mesmo sexo. O adjunto adverbial de adição também, utilizado no $\S 4 .^{\circ}$ do art. 226 da CF, é uma conjunção aditiva, a evidenciar que se trata de uma enumeração exemplificativa da entidade familiar. Só as normas que restringem direitos têm de ter interpretação de exclusão. (DIAS, 2001, p. 11).

O artigo 226, § 3..$^{\circ}$, da Constituição de 1988, diz que "é reconhecida a união estável entre o homem e a mulher como entidade familiar", fazendo com que a diversidade de sexos seja um pressuposto de fato para a existência de tal união. Isso caracteriza norma marcadamente discriminatória, pois viola o princípio da igualdade que, no artigo $3 .^{\circ}, \mathrm{IV}$, do mesmo diploma, proíbe o preconceito e a diferenciação das pessoas em razão de seu sexo, vale dizer, de sua orientação sexual.

Alçado à categoria de princípio fundamental, o princípio constitucional da igualdade confere proteção específica no que diz respeito às questões de gênero, assim como o artigo $5^{\circ}$, I, do diploma constitucional, veda qualquer tratamento desigual e de cunho discriminatório quando o motivo para tal diferenciação for o sexo:

Entre a união estável e a união homoafetiva, evidenciam-se, em alto grau, as similitudes que caracterizam ditas modalidades de agregação familiar; considerando a hipótese de haver a supressão do requisito da diferenciação de sexos, que se traduz na expressão entre homem e mulher, estar-se-ia diante de verdadeira união estável, inclusive com as características da convivência pública, contínua e duradoura. (PINHEIRO, 2009).

Não fosse a exigência imposta pela lei quando, ao conceituar união estável, exigiu a diversidade de sexos, em nada mais ela seria diferente das uniões homoafetivas.

Alguns doutrinadores entendem que as uniões entre pessoas do mesmo sexo devem ser enquadradas, por analogia, à união estável, eis que não havendo 
previsão legal expressa relativamente aos direitos e deveres dos companheiros do mesmo sexo, mas, por existir semelhança entre os dois relacionamentos no sentido de possuírem por base o afeto, o companheirismo e a publicidade, é de se aplicar a legislação concernente à união estável prevista no artigo 1.723 e os seguintes do novo Código Civil.

Seguramente não há diferença alguma entre as relações heteroafetivas e homoafetivas, exceto a diversidade de sexos, e ambos os relacionamentos possuem o mesmo propósito: a livre escolha na constituição de sua família, como a busca pela segurança jurídica e sua identidade social, ou seja, da cidadania.

Embora o reconhecimento das uniões homoafetivas enfrente enorme resistência, o Estado não pode deixar de protegê-las. Subtrair juridicidade a um fato social implica deixar o indivíduo à margem da própria cidadania, o que descaracterizaria um Estado democrático de direito, que é aquele que se empenha em garantir o respeito das liberdades civis por meio de uma proteção jurídica.

Não havendo exclusão expressa na lei às uniões homoafetivas, somos levados ao que Bobbio (2008) chamou de norma geral exclusiva, que é uma das premissas básicas do pensamento kelseniano, ao colocar afirmar que "tudo que não está explicitamente proibido, está, implicitamente permitido".

\section{Assim,}

Se duas pessoas têm uma vida em comum, cumprindo deveres de mútua assistência, verdadeiro convívio caracterizado por amor e respeito, a identidade meramente biológica de sexos do par não pode impedir que se reconheçam direitos e se imponham obrigações recíprocas. O direito precisa atentar para as situações do mundo fático. (DIAS, 2008).

Como afirma o respeitável ministro Massami Uyeda:

[...] os fatos da vida são dinâmicos e muitas vezes não encontram previsão em leis formais; e qualquer lesão sofrida pela sociedade deve ser apreciada pelo Judiciário; caso haja a omissão legal, cabe ao juiz decidir de acordo com a analogia, os costumes e os princípios gerais de direito, não podendo jamais eximir-se de julgar. (UYEDA, 2008).

As relações afetivas entre pessoas do mesmo sexo interessam à sociedade brasileira à medida que ela se constitui em um Estado democrático de direito e pretende salvaguardar os direitos fundamentais dos indivíduos que a compõem. As uniões homoafetivas, como fato social que são, anteciparam-se ao fato jurídico, cumprindo ao juiz, portanto, a tarefa de dizer o direito porque há regras que possibilitam ao aplicador integrar o sistema jurídico de modo a obter uma completude lógico-formal do sistema.

Deixar de reconhecer as uniões entre pessoas do mesmo sexo afronta os princípios da dignidade da pessoa humana e da igualdade jurídica, em que se desconsideram as diferenças pessoais e a própria democracia substancial, que subordina os atos e as leis aos conteúdos dos direitos fundamentais.

Desnecessário elencar razões para impedir o tratamento diferenciado dado a essas uniões; a lógica é exatamente inversa: inexistindo motivo legítimo a exigir distinção, o tratamento igualitário deverá ser empregado como regra. Com a restrição de que, em um Estado pluralista e democrático, tais motivos devem ter o amparo de argumentos de razão pública e não por visões de mundo pessoais, de ordem moral tampouco religiosa.

Ainda que apoiadas por incontáveis asseclas ou mesmo pela maioria, tais concepções não podem ser impostas pelo poder público. Ao adotar uma postura de indiferença, o direito contribui para que se materialize uma indesejável situação de insegurança que revela um juízo de desvalor em relação aos indivíduos envolvidos nas uniões homoafetivas.

Em uma sociedade democrática, tanto o Estado quanto o direito têm a função de asseverar a todos os indivíduos o desenvolvimento de sua personalidade, permitindo a cada um o direito de escolha e a realização de seus projetos pessoais. Deste modo, o poder público não pode perpetrar, nem validar a discriminação e o preconceito; ao contrário, é seu dever enfrentá-los de modo consistente, asseverando segurança e apoio aos grupos em condição de vulnerabilidade.

O mundo mudou, a sociedade mudou e, nos últimos anos, a aceitação das parcerias homossexuais tem se expandido, havendo um movimento inegável de progressiva legitimação social das uniões homoafetivas. E como consequência destas mudanças surge a decisão do Supremo Tribunal Federal na Ação Direta de Inconstitucionalidade 4.277 e Arguição de Descumprimento de Preceito Fundamental 
132, que reconheceu a união estável homoafetiva e a equiparou como entidade familiar, consequentemente tutelando direitos indisponíveis.

Assim sendo, as uniões de pessoas do mesmo sexo passam a merecer, como entidade familiar, a mesma proteção que o Estado dispensa às uniões estáveis heteroafetivas.

Esta decisão veio trazer novos rumos ao direito de família, aproximando a justiça da realidade social atual. $\mathrm{O}$ tribunal ao reconhecer estes direitos responde a um segmento da sociedade cujos direitos, durante longo tempo, foram ignorados, cuja dignidade foi ofendida, cuja identidade foi denegada e cuja liberdade foi oprimida.

Pautado nestas questões, o Supremo Tribunal Federal, em decisão histórica, vem romper com paradigmas e conceitos ultrapassados, reconhecendo como entidades familiares as uniões antes criminalizadas.

\section{Conclusão}

A família se encontra inserida em um espaço sociocultural que necessita de reconstrução e renovação constantes. É um fenômeno social e, como tal, produz efeitos jurídicos os mais diversos, traz inovações, criando dissensões que impelem tanto o mundo sociológico quanto o mundo jurídico, se posicionando sempre à frente das normas e convenções, esquadrinhando seu próprio espaço e buscando soluções para sua evolução.

Entre as uniões homoafetivas e as uniões estáveis existe estreita relação, sendo suas bases de sustentação idênticas à de outra família qualquer, cabendo, portanto, a utilização da analogia para que a ausência normativa possa ser sanada.

Infelizmente, os aplicadores do direito ainda insistem em conferir a esses relacionamentos caráter meramente negocial, excluindo-os da esfera familiar. Porém, por estarem sob o amparo da Constituição Federal, em nenhuma hipótese poderiam sofrer exclusão ou discriminação, pois isso caracterizaria inconstitucionalidade e violação de princípios.

Embora as divergências doutrinárias e jurisprudenciais perseverem somadas ao silêncio do legislador, que, incorporando a função de guardião de uma conservadora moral, insiste em condenar à invisibilidade tudo o que foge ao modelo convencional, inconcebível qualquer tipo de incitação à intolerância, ao preconceito, ao desrespeito, que apenas fortalece a desigualdade entre as pessoas. Definitivamente, ninguém deve ser privado de direitos nem suportar cerceamentos de ordem jurídica objetivados por sua orientação sexual.

O Poder Judiciário não pode se esquivar de enxergar e incorporar o novo, tampouco se eximir quando invocado alegando a lacuna legal e insistir em uma conduta juridicamente reducionista, excludente, arbitrária em relação a determinados segmentos minoritários. O magistrado tem o dever de aplicar o direito, utilizando todas as ferramentas legais que estiverem ao seu alcance para que a justiça possa ser feita.

Em decisão histórica proferida recentemente, o Supremo Tribunal Federal, empregando a analogia e invocando princípios fundamentais, em votação unânime reconhece o direito personalíssimo à orientação sexual, proclamando a constitucionalidade das uniões homoafetivas, legitimando-as como entidade familiar, concedendo-lhes verdadeiro estatuto de cidadania, bem como permitindo que se extraiam, em favor de parceiros homossexuais, relevantes consequências no plano do Direito e na esfera das relações sociais.

Ninguém pode ser tido como cidadão de segunda classe porque assentiu em adotar modelo de vida divergente do que a maioria tenha estabelecido como válido. O que pode haver de mais íntimo é o afeto nutrido por alguém e, ainda, aqueles que vivem em uniões de afeto com pessoas do mesmo sexo não podem ser desigualados em sua cidadania.

Desse modo, impedir o reconhecimento e amparo a essas uniões seria afastar o entendimento contemporâneo de família consagrada no afeto, condenando assim ao desamparo a pessoa humana que é o centro e o sentido de todo o sistema jurídico.

\section{Referências}

BITTAR FILHO, C. Alberto. A evolução da instituição familiar no direito brasileiro. Disponível em: <http:// orbita.starmedia.com>. Acesso em: 12 junho 2008.

BOBBIO, Norberto. Teoria do ordenamento jurídico. Disponível em: $<$ http://jus2.uol.com.br/doutrina/texto. asp? > . Acesso em: 11 maio 2008. 
CARBONERA, Silvana Maria. O papel jurídico do afeto nas relações de família. Rio de Janeiro: Renovar, 1998.

CHILETTO, Maria Claudia Cairo. Uniões homoafetivas: uma nova concepção de família na perspectiva do direito civil-constitucional. Disponível em: $<$ http://fdc.br/Arquivos/ Mestrado/Dissertacoes/Integra/MariaClaudiaCairo.pdf $>$. Acesso em: 28 junho 2012.

DIAS, Maria Berenice. Direito das famílias: monogamia não é um princípio, é só marco regulador. Disponível em: $<$ www.conjur.com>. Acesso em: 13 dezembro 2008.

. União homossexual: aspectos sociais e jurídicos.

Revista Brasileira de Direito de Família, Porto Alegre, v. 4, jan./mar. 2000.

. Uniões homoafetivas: uma realidade que o Brasil insiste em não ver. Disponível em: <www.tj.ro.gov.br/ emeron/revista $>$. Acesso em: 20 dezembro 2008.

FERNANDES, Taísa Ribeiro. Uniões homossexuais: efeitos jurídicos. Disponível em: <http:www.lfg.com.br/ public_html/article>. Acesso em: 07 outubro 2008.

FRANCHINI, João Gisberto. Da ocorrência de danos morais entre cônjuges ou conviventes e da sua reparabilidade no direito brasileiro. Revista Jurídica Cesumar, v. 4, n. 1, 2004, p. 199-227

HIRONAKA, Giselda Maria Fernandes Novaes. Família e casamento em evolução. Disponível em: <http://www. jusnews.com.br/>. Acesso em: 06 julho 2008.

KÜMPEL, Vitor Frederico. Palestra ministrada em 21 jan. 2008. Disponível em: <www.uj.com.br>. Acesso em: 23 abr. 2010.

LIMA, Maria Cristina de Brito. União estável. Disponível em: <http://www.titoiff>. Acesso em: 17 fevereiro 2008.

MELO, Elaine Cristina de Oliveira E. Um novo modelo de família: aspectos sociojurídicos da união entre homossexuais. Disponível em: <http://jus2.uol.com.br/>. Acesso em: 01 fevereiro 2009.

OLIVEIRA, José Sebastião. Fundamentos constitucionais do direito de família. São Paulo: RT, 2002.

OLIVEIRA, Vera Lucia Vieira Camillo de. Nada mais é do que paternidade afetiva, não necessariamente biológica. Disponível em: <www.jcamillo.com.br/>. Acesso em: 12 novembro 2008.

PEREIRA. Rodrigo da Cunha. O direito da família do século XXI. Disponível em: <http://www.pailegal.net/ forum/view.php? $\mathrm{t}=5726 \& \mathrm{sid}=\mathrm{f} 28 \mathrm{cecf} 734 \mathrm{cfee} 0083 \mathrm{fb} 0 \mathrm{~b} 626$ $44 \mathrm{~b} 27 \mathrm{cb}>$. Acesso em: 30 setembro 2008.

PINHEIRO, Fabíola Christina de Souza. Uniões homoafetivas: do preconceito ao reconhecimento como núcleo de família. Disponível em: < http://jus2.uol.com. br/>. Acesso em: 01 fevereiro 2009.
PRADO, Danda. O que é família? São Paulo: Brasiliense, 1995.

SIMON, Romeu. A evolução histórica das uniões informais e do conceito de família. Disponível em: $<$ http:// www.direitonet.com.br>. Acesso em: 04 outubro 2008.

UYEDA, Massami. União estável homossexual: empate no julgamento adia decisão sobre união estável homoafetiva no STJ. Disponível em: $<$ www.azevedosette.com.br $>$. Acesso em: 17 setembro 2008. 